\title{
Obligación sindical de rendir cuentas
}

Trade Union Obligation to be Accountable

Prestação de contas da união

DOI: http://dx.doi.org/10.23913/ricsh.v6i11.122

Gloria Aurora de las Fuentes Lacavex

Facultad de Ciencias Administrativas y Sociales, Universidad Autónoma de Baja California, México

gloriaaurora@uabc.edu.mx

María Aurora de la Concepción Lacavex Berumen Facultad de Derecho, Universidad Autónoma de Baja California, México

axevacal@uabc.edu.mx

\section{Resumen}

Los sindicatos, regulados por las normas laborales y las normas burocráticas, tienen en el texto constitucional el fundamento de su existencia. Las leyes que los regulan les obligan a rendir cuentas a sus agremiados.

Las disposiciones jurídicas expedidas recientemente en México, relativas a la transparencia y accesos a la información pública, incluyen a los sindicatos como sujetos obligados a transparentar y permitir al acceso a su información en el caso de recibir y ejercer recursos públicos.

En este artículo se analiza qué son los recursos públicos, si los sindicatos realmente los reciben y si la obligación de transparentar y permitir el acceso a su información es jurídicamente correcta. Palabras clave: sindicatos, transparencia, obligación. 


\section{Abstract}

Labor unions, regulated by labor standards and bureaucratic rules, have as the foundation of their existence the constitutional text. The laws that regulate them force them to be accountable to their members.

The legal provisions recently issued in Mexico, regarding transparency and access to public information, include the unions as subjects forced to be transparent and allow access to their information in the case of receiving and exercising public resources.

In this article, it is analyzed what public resources are, if the unions really receive them and if the obligation to make them transparent and allow access to their information is legally correct. Key words: labor unions, transparency, accountability.

\section{Resumo}

Sindicatos, as normas de trabalho regulamentados e regras burocráticas estão na Constituição o fundamento da sua existência. As leis que regulam os obrigam a prestar contas aos seus membros.

Normas legais emitiu recentemente no México, sobre transparência e acesso à informação pública, incluindo os sindicatos como requerido para ser transparente e permitir o acesso às suas informações no caso de receber e guardar recursos públicos assunto.

Este artigo discute como são recursos públicos, se os sindicatos realmente são e se a obrigação de ser transparente e permitir o acesso a sua informação é legalmente correto. Palavras-chave: sindicatos, obrigação de transparência.

Fecha Recepción: Agosto $2016 \quad$ Fecha Aceptación: Diciembre 2016 


\section{Introducción}

En México, Alberto Trueba Urbina menciona entre los antecedentes del sindicalismo "la sociedad particular de socorros mutuos... posteriormente se estimó que el sistema cooperativo de consumo era más benéfico que el mutualista. El 16 de septiembre de 1872 se fundó la primera asociación de tipo profesional, círculo de obreros" (Trueba Urbina, A., 1981, p. 351).

Esta organización llegó a contar en sus filas, en octubre de 1874, con más de ocho mil trabajadores, en su mayoría artesanos y obreros de hilados y tejidos. El 5 de marzo de 1876 se fundó la Confederación de Asociaciones de Trabajadores de los Estados Unidos Mexicanos, la cual fortaleció la unidad de los trabajadores, constituyéndose después, en 1890, en la Orden Suprema de Empleados Ferrocarrileros Mexicanos, la Unión de Mecánicos Mexicanos, la Sociedad de Hermanos Caldereros Mexicanos, la Liga Mexicana de Empleados de Ferrocarril y otras más. En Cananea se fundó la Unión Liberal Humanidad y, en Orizaba, Veracruz, el Gran Círculo de Obreros Libres; ambos organismos fueron los protagonistas de las huelgas de Cananea y Río Blanco. En 1911 se constituyó la Confederación Tipográfica de México. En 1912 se fundó el Departamento del Trabajo y se estableció la Casa del Obrero Mundial, que en 1913 exigió (Lastra Lastra, J.M., 2002, p. 38) “por primera vez en el país, el 1o. de mayo, la jornada de ocho horas y el descanso dominical" (Trueba Urbina, A., 1981, p. 352).

La Constitución política vigente en el país se promulgó el 5 de febrero de 1917, después de la celebración del Congreso Constituyente en la ciudad de Querétaro, durante diciembre de 1916 y enero de 1917. De estos debates destacan los celebrados los días 12, 19 y 23 de diciembre de 1916, en los que se discutieron los asuntos relativos al trabajo, para ser elevados a rango constitucional en el artículo 123, por primera vez en el mundo.

A partir de la lucha política de los burócratas, que se había actualizado entre otros ordenamiento jurídicos en el Estatuto Cardenista, se incluyó como esencial a la categoría de norma escrita en la

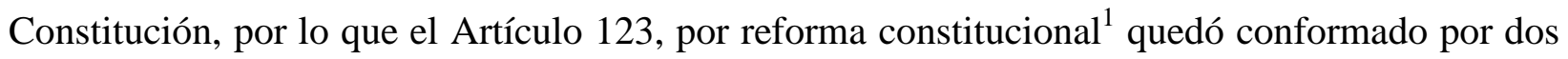
Apartados: el Apartado A en el que se sustenta el Derecho del Trabajo, y el Apartado B que es el fundamento del Derecho Burocrático Federal.

\footnotetext{
${ }^{1}$ Diario Oficial de la Federación (DOF), 5 de diciembre de 1960.
} 
En ambos apartados se garantiza el derecho de los trabajadores a constituir sindicatos.

La Ley General de Transparencia y Acceso a la Información Pública (LGTAIP) ${ }^{2}$ y la Ley Federal de Transparencia y Acceso a la Información Pública (LFTAIP) ${ }^{3}$ incluyen a los sindicatos como sujetos obligados a transparentar y permitir el acceso a su información en el caso de recibir y ejercer recursos públicos.

La rendición de cuentas se define como la obligación permanente de los mandatarios o agentes de informar a sus mandantes o principales de los actos que llevan a cabo como resultado de una delegación de autoridad que se realiza mediante un contrato formal o informal y que implica sanciones en caso de incumplimiento. Los mandantes o principales supervisan también a los mandatarios o agentes para garantizar que la información proporcionada sea fidedigna (Ugalde, L.C., 2015, p. 14).

La transparencia es una característica que abre la información de las organizaciones políticas y burocráticas al escrutinio público, mediante sistemas de clasificación y difusión que reducen los costos de acceso a la información del gobierno. Sin embargo, la transparencia no implica un acto de rendir cuentas a un destinatario específico, sino la práctica de colocar la información en la 'vitrina pública' para que aquellos interesados puedan revisarla, analizarla y, en su caso, usarla como mecanismo para sancionar en caso de que haya anomalías en su interior. La transparencia es un instrumento de un sistema global de rendición de cuentas, mas sería impreciso usarlo como sinónimo de aquel (Ugalde, L.C., 2015, p. 14).

La rendición de cuentas es un tema de muy reciente estudio en México desde una perspectiva de la ciencia política. Desde un enfoque histórico, . . . las constituciones de 1824 y 1857 definieron la importancia de organizar y controlar el poder. La primera separó el poder y adoptó mecanismos de pesos y contrapesos, como el veto presidencial o el llamamiento a cuentas que podía hacer el Congreso al Poder Ejecutivo. La de 1857 otorgó grandes poderes al Congreso para exigir cuentas al Ejecutivo (lo que resultó un

${ }^{2}$ DOF, 4 de mayo de 2015, sin reforma.

${ }^{3}$ DOF, 9 de mayo de 2016, una reforma del 27 de enero de 2017. 
obstáculo para la gobernabilidad del país) y dispuso, por primera vez, la existencia constitucional de garantías individuales. Los principios de los que hoy se conoce como rendición de cuentas horizontal eran incorporados a la vida institucional de nuestro país (Ugalde, L.C., 2015, p. 49).

Desde el Constituyente de 1917, la expresión 'rendición de cuentas' formaba parte del lenguaje en los debates parlamentarios, aunque de manera limitada, según consta en los registros de la Cámara de Diputados. El Plan Nacional de Desarrollo de la administración de Ernesto Zedillo propone un esfuerzo profundo que prevea una forma clara de rendición de cuentas y asegure que quienes, en el ejercicio de una responsabilidad pública, transgredan la ley o las normas de desempeño del servicio público, sean sancionados conforme a la ley. El Plan Nacional de Desarrollo de Vicente Fox dio seguimiento al tema; el gobierno está obligado a establecer los mecanismos e instrumentos que le permitan informar y rendir cuentas a los ciudadanos, a los demás poderes y a cada uno de los órdenes de gobierno (Ugalde, L.C., 2015, p. 51).

El $1^{\circ}$ de septiembre de 2012, el presidente Felipe Calderón presentó al Congreso de la Unión iniciativa preferente para reformar la Ley Federal del Trabajo.

La iniciativa del Ejecutivo pretendía democratizar a los sindicatos y fomentar la transparencia. Respecto del primer aspecto, la iniciativa agregaba el artículo 364 bis. En esta misma tónica, la iniciativa señalaba en el artículo 371, fracción IX, que los estatutos de los sindicatos debían contener: 'número de miembros de la directiva y procedimiento para su elección, que deberá ser mediante voto libre, directo y secreto' (Anzures Gurría, J.J., 2014, p. 27).

Respecto a la cuestión de la transparencia sindical, la iniciativa del Ejecutivo pretendía fortalecer la rendición de cuentas por parte de las directivas de los sindicatos a través de distintas medidas, contenidas, sobre todo, en el artículo 373. Entre otras cosas, se preveía que el sindicato entregara a todos los trabajadores sindicalizados un resumen de los resultados de la administración del patrimonio sindical y que la rendición de cuentas incluyera, por lo menos, la situación de los ingresos por cuotas sindicales y otros bienes, así como su destino (Anzures Gurría, J.J., 2014, pp. 27-28). 
En relación a esta obligación sindical, la doctora María Patricia Kurczyn Villalobos, comisionada del Instituto Nacional de Transparencia, Acceso a la Información y Protección de Datos Personales (INAI), señaló que "cuando los sindicatos reciben recursos públicos se genera el derecho de cualquier persona, no necesariamente un trabajador, de solicitar información sobre su uso y destino. Asimismo expresó que en la Ley Federal de Transparencia que se discutirá en el Congreso, junto con la vigente Ley General de Transparencia, se tendrán que conciliar los procedimientos para que los sindicatos cumplan las obligaciones de transparencia (Aristegui Noticias "Sindictos deben rendir cuentas por obligación constitucional: INAI.", 2 de septiembre de 2015. http://aristeguinoticias.com/0209/mexico/sindicatos-deben-rendir-cuentas-porobligacion-constitucional-inai/Consultado: 3 de junio de 2017).

\section{Método}

Este artículo es una investigación documental donde se analizan la metodología de la investigación jurídica y los diversos instrumentos jurídicos relacionados con la obligación que se ha dado a los sindicatos en México de rendir cuentas sobre la transparencia en el ejercicio de los recursos públicos.

Se siguieron los pasos que corresponden a un trabajo de investigación documental: elaboración del plan de trabajo (donde se elige y delimita el tema), redacción de hipótesis, elaboración del esquema de trabajo e identificación de las fuentes de consulta preliminares. Posteriormente se procedió a la elaboración de fechas de fuente y fichas de trabajo, las cuales se analizaron y se redactó el artículo, desarrollando las conclusiones que se consideraron pertinentes (Cfr.: Hernández Estévez y López Durán, 1998, 65 y sigts.; Baena, 1998, 13 y sigts.; Rojas Soriano, 1979, 68 y sigts.) 


\section{Resultados}

\section{Contexto normativo}

\section{Sindicatos}

La Constitución Política de los Estados Unidos Mexicanos (CPEUM) ${ }^{4}$ regula en el Título Sexto, Del Trabajo y de la Previsión Social, en el Artículo 123, tanto en el Apartado A como en el Apartado B, respectivamente, a los sindicatos, constituidos por trabajadores que prestan un servicio personal subordinado, ya sea a los patrones particulares o a los poderes de la unión.

Con respecto a los trabajadores que prestan ese servicio personal subordinado a los municipios de los diversos estados del país, así como a los propios estados, la CPEUM establece en los numerales 115, fracción VIII y 116, fracción VI, respectivamente, una remisión expresa al Artículo 123.

Estas garantías sociales contenidas en la Constitución Mexicana se desarrollan en las leyes reglamentarias.

Sobre los trabajadores que prestan un servicio personal subordinado a los patrones particulares y a los organismos descentralizados de los tres niveles de gobierno, ${ }^{5}$ los sindicatos se regulan en la Ley Federal del Trabajo (LFT), ${ }^{6}$ en el Título Séptimo, Capítulos I y II, en los numerales 354 a 357.

En cuanto a los trabajadores que prestan un servicio personal subordinado a los poderes de la unión, es la Ley Federal de los Trabajadores al Servicio del Estado (LFTSE) ${ }^{7}$ la que regula los sindicatos, en el Título Cuarto, De la Organización Colectiva de los Trabajadores y de las Concisiones Generales de Trabajo, Capítulo I, artículo 67.

Las leyes burocráticas locales, en acatamiento de los artículos 115 y 116 de la CPEUM, regulan la relación jurídica individual y colectiva que se establece entre los trabajadores y la dependencia gubernamental correspondiente, así como los órganos jurisdiccionales competentes y las normas

\footnotetext{
${ }^{4}$ DOF 5 de febrero de 1917, reformada 229 ocasiones, al 20 de enero de 2017, la más reciente el 15 de agosto de 2016.

${ }^{5}$ Jurisprudencia $1 / 96$ del Pleno de la Suprema Corte de Justicia de la Nación. Semanario Judicial de la Federación y su Gaceta. Tomo III, febrero de 1996, p. 52, registro 200199.

${ }^{6}$ DOF 1 de abril de 1970, reformada 27 ocasiones al 20 de enero de 2017, la más reciente el 12 de junio de 2015.

7 DOF 28 de diciembre de 1963, reformada 20 ocasiones, al 20 de enero de 2017, la más reciente el 2 de abril de 2014.
} 
procesales aplicables. Rigen en el país treinta y un ordenamientos jurídicos estatales y tres municipales.

Cabe mencionar que la regulación de la obligación de rendir cuentas por parte de los sindicatos es imprecisa y, en algunos casos, se encuentra únicamente en los estatutos.

Por ejemplo:

- Ley de los Trabajadores al Servicio de los Poderes del Estado y Municipios de Baja California Sur. ${ }^{8}$ Dispone que es obligación del sindicato proporcionar los informes que, en cumplimiento de la Ley, solicite el Tribunal de Conciliación y Arbitraje, sin hacer referencia a los agremiados.

- Ley de los Trabajadores al Servicio de las Instituciones Públicas del estado de San Luis Potosí. ${ }^{9}$ Establece que es obligación del sindicato atender la solicitud sobre informes que le envíe el Tribunal Estatal de Conciliación y Arbitraje, siempre que se trate de las actuaciones inherentes al sindicato, así como las demás que le señalen sus respectivos estatutos y ordenamientos de la materia.

- Ley de los Trabajadores al Servicio del Ayuntamiento del Municipio de Puebla. ${ }^{10}$ Establece como obligación expresa del sindicato, la de informar por lo menos cada tres meses a sus agremiados del estado que guardan las finanzas del sindicato y la aplicación de los recursos.

Adicionalmente a la personalidad jurídica que la legislación del trabajo y la legislación burocrática otorgan a los sindicatos, el Código Civil Federal $(\mathrm{CCF})^{11}$ los reconoce como personas morales en los artículos 25, fracción IV, 26, 27 y 28, del Título Segundo, De las Personas Morales, del Libro Primero, De Las Personas.

Los Códigos Civiles de las entidades federativas del país, también reconocen como persona moral a los sindicatos.

\footnotetext{
${ }^{8}$ Boletín Oficial del Gobierno del estado de Baja California Sur, 23 de febrero de 2004, reformada en dos ocasiones, la más reciente el 31 de julio de 2012.

${ }^{9}$ Sección segunda del Periódico Oficial del estado de San Luis Potosí, 8 de enero de 1996, reformada en nueve ocasiones, la más reciente el 10 de junio de 2014.

${ }^{10}$ Periódico oficial del estado de Puebla, 11 de diciembre de 2013; no ha sido reformada.

${ }^{11}$ DOF en cuatro partes los días 26 de mayo, 14 de julio, 3 y 31 de agosto de 1928. Reformado en 53 ocasiones, al 20 de enero de 2017, la más reciente el 24 de diciembre de 2013.
} 
Como ejemplo se mencionan:

- Código Civil del Estado de México, ${ }^{12}$ establece en el Libro Segundo, de las Personas, en el Título Tercero, Personas Jurídicas Colectivas, en el numeral 2.10, que se consideran personas jurídicas colectivas a aquellas reconocidas por las leyes federales y de las demás entidades de la república. De lo anterior se deprende que los sindicatos tienen el carácter de persona jurídica colectiva.

- Código Civil para el estado libre y soberano de Morelos, ${ }^{13}$ regula como personas jurídicas colectivas a los sindicatos, las asociaciones profesionales y las demás a que se refieren las fracciones XVI, apartado A, y X, apartado B, del artículo 123 de la Constitución Federal, en el artículo 61, Capítulo II, de las Personas Jurídicas Colectivas, en el Título Primero, de las Personas Jurídicas, del Libro Segundo, de las Personas.

\section{Rendición de cuentas}

Los sindicatos federal y local, laboral y burocráticos tienen obligación de rendir cuentas a sus integrantes.

La LFT dispone en el numeral 373 que la directiva de los sindicatos, en los términos que establezcan sus estatutos, debe rendir a la asamblea cada seis meses, por lo menos, cuenta completa y detallada de la administración del patrimonio sindical. La rendición de cuentas debe incluir la situación de los ingresos por cuotas sindicales y otros bienes, así como su destino. Esta obligación no es dispensable.

Por lo que hace a la LFTSE, el artículo 77 regula las obligaciones de los sindicatos, entre las que se establece la de proporcionar los informes que solicite el Tribunal Federal de Conciliación y Arbitraje y el artículo 80 dispone que la directiva del sindicato es responsable ante éste y respecto de terceras personas en los mismos términos que lo son los mandatarios en el derecho

\footnotetext{
${ }^{12}$ Periódico oficial, Gaceta del Estado de México, 7 de junio de 2002, reformado 46 ocasiones, al 20 de enero de 2017, la más reciente el 26 de septiembre de 2016.

${ }^{13}$ Periódico oficial del estado de Morelos, 13 de octubre de 1993, reforma más reciente del 11 de diciembre de 2008.
} 
común. Si bien en la LFTSE no se contiene expresamente la obligación de los sindicatos de rendir cuentas a sus agremiados, ésta se establece en los estatutos correspondientes. En términos semejantes se regula esta obligación en la normatividad burocrática local.

La LGTAIP dispone en el numeral 6 que éste es un ordenamiento jurídico de orden público y de observancia general en toda la República, en materia de transparencia y acceso a la información y que tiene por objeto establecer los principios, bases generales y procedimientos para garantizar el derecho de acceso a la información en posesión de cualquier autoridad, entidad, órgano y organismo de los poderes Legislativo, Ejecutivo y Judicial, órganos autónomos, partidos políticos, fideicomisos y fondos públicos, así como de cualquier persona física, moral o sindicato que reciba y ejerza recursos públicos o realice actos de autoridad de la Federación, las Entidades Federativas y los municipios.

Esta ley dispone en el numeral 70 que en la ley federal y de las entidades federativas debe contemplarse que los sujetos obligados pongan a disposición del público y mantengan actualizada, en los respectivos medios electrónicos, de acuerdo con sus facultades, atribuciones, funciones u objeto social, según corresponda, la información, por lo menos, de los temas, documentos y políticas, entre las que, en relación a los sindicatos se señalan las condiciones generales de trabajo, contratos o convenios que regulen las relaciones laborales del personal de base o de confianza, así como los recursos públicos económicos, en especie o donativos, que sean entregados a los sindicatos y ejerzan como recursos públicos.

Esta disposición se complementa con los artículos 78 y 79, que se relacionan, en materia laboral, con lo dispuesto en el numeral 40 de la Ley Orgánica de la Administración Pública Federal (LOAPF), ${ }^{14}$ por lo que se refiere a las atribuciones de la Secretaría del Trabajo y Previsión Social (STPS), así como con los artículos 365 bis, 371, 373, 391 bis, 523, 614, 617 y 621 de la LFT, en relación a la obligación de las autoridades laborales de hacer pública la información referente al registro de sindicatos, contratos colectivos de trabajo y reglamentos interiores de trabajo, que se cumplen en las páginas electrónicas de la STPS (Secretaría del Trabajo y de Previsión Social http://www.gob.mx/stps/ Consultado: 13 de febrero de 2017) y de la Junta Federal de

\footnotetext{
${ }^{14}$ DOF 29 de diciembre del 1976. Reformada en 55 ocasiones, la más reciente el 19 de diciembre de 2016.
} 
Conciliación y Arbitraje (Junta Federal de Conciliación y Arbitraje. http://www.gob.mx/jfca Consultado: 1 de febrero de 2107).

En estos mismos términos, la Segunda Sala de la Suprema Corte de Justicia de la Nación (SCJN) dictó dos tesis aisladas, en las que sostiene que los artículos 391 bis y 365 bis, en relación a la publicidad de contratos colectivos de trabajo, registro de sindicatos y de sus estatutos, no vulneran los artículos 6, 16 segundo párrafo y 123, Apartado A, fracción XVI constitucionales. ${ }^{15}$

Esta obligación también se regula en materia laboral local en relación a la dependencia local en materia de trabajo y previsión social, cuya denominación puede variar según la entidad federativa de que se tratase, y a las Juntas Locales de Conciliación y Arbitraje.

En materia burocrática federal se relacionan con lo indicado en los numerales 118 a $124 \mathrm{C}$ de la LFTSE, que se cumplen en materia de trasparencia en la página electrónica del Tribunal Federal de Conciliación y Arbitraje (TFCA). (Tribunal Federal de Conciliación y Arbitraje. http://tfca.gob.mx/es/TFCA/ Consultado: 13 de febrero de 2017).

Esta misma obligación se regula en relación a los órganos jurisdiccionales locales en materia burocrática estatal y municipal en los estados del país.

Para el caso de incumplimiento de los sujetos obligados, la LGTAIP regula medidas de apremio y sanciones en los artículos 201 y 209.

La LFTAIP dispone en el artículo 1 que es un ordenamiento jurídico de orden público y tiene por objeto proveer lo necesario en el ámbito federal, para garantizar el derecho de acceso a la información pública en posesión de cualquier autoridad, entidad, órgano y organismo de los poderes Legislativo, Ejecutivo y Judicial, órganos autónomos, partidos políticos, fideicomisos y fondos públicos, así como de cualquier persona física, moral o sindicato que reciba y ejerza

\footnotetext{
${ }^{15}$ Tesis: 2a. ClI/2014 (10a.) Segunda Sala. Gaceta del Semanario Judicial de la Federación. Décima Época. Libro 11, octubre de 2014, Tomo I, p. 1096. Registro: 2007572 y Tesis: 2a. Cl/2014 (10a.) Segunda Sala. Gaceta del Semanario Judicial de la Federación. Décima Época. Libro 11, octubre de 2014, Tomo I, p. 1105. Registro: 2007579.
} 
recursos públicos federales o realice actos de autoridad, en los términos previstos por la CPEUM y la LGTAIP.

El numeral 74 establece que respecto de las obligaciones específicas que deben cumplir las personas físicas o morales que reciben y ejercen recursos públicos o realicen actos de autoridad se debe estar a lo dispuesto en el Capítulo IV del Título Quinto de la Ley General. Los sindicatos que reciban y ejerzan recursos públicos deben mantener actualizada y accesible, en los respectivos sitios de Internet, la información aplicable de los artículos 70 y 79 de la Ley General.

Este ordenamiento también regula, para el caso de incumplimiento, medidas de apremio y sanciones, en los numerales 174 y 187 , respectivamente.

El Instituto Nacional de Trasparencia, Acceso a la Información y Protección de Datos Personales (INAI), dictó acuerdo en el que aprueba el padrón de sujetos obligados al ámbito federal, en términos de la LGTAIP, en la que se contienen 882 sujetos obligados, entre los que se cuentan 147 sindicatos. (Instituto Nacional de Trasparencia, Acceso a la Información y Protección de Datos Personales. DOF ACUERDO ACT-EXT-PUB/02/05/2016.2 Sindicatos. Nos. 60100 a 60256. http://dof.gob.mx/nota_detalle.php?codigo=5436061\&fecha=04/05/2016 Consultado: 15 de febrero de 2017).

\section{Recursos públicos}

Todo ser humano tiene la obligación de realizar una actividad lícita que le permita obtener los satisfactores que se requieren para que sus necesidades y las de su familia desaparezcan. Esta actividad se ha transformado a lo largo del tiempo, hasta alcanzar la complejidad económica que tiene hoy en día.

De igual forma, el Estado, los gobiernos, para cumplir con las atribuciones y obligaciones que tienen consignadas en los documentos constitucionales y legales, requieren de ingresos.

Los ingresos del Estado se dividen en dos grupos: los que provienen de bienes y actividades del Estado, y los que provienen del ejercicio de poderes inherentes a la soberanía. 
Los ingresos tributarios son impuestos, aportaciones de seguridad social, derechos, contribuciones especiales o de mejoras, tributos o contribuciones accesorias.

Los ingresos financieros son empréstitos, emisión de moneda, emisión de bonos de deuda pública, amortización y conversión de la deuda pública, monetarias y renegociaciones, devaluación. Productos y derechos, expropiaciones, decomisos, nacionalizaciones, privatización. Se emplea la expresión recursos públicos para definir a todos los ingresos que el Estado percibe, de cualquier naturaleza que sean, con el objeto de financiar el gasto público. Estos ingresos pueden ser impuestos, tasa y contribuciones especiales.

La CPEUM hace referencia a diversos conceptos en la materia: recursos públicos, recursos económicos, recursos federales, recursos monetarios, recursos ordinarios, recursos de la Federación, recursos del Presupuesto de Egresos de la Federación, recursos de los Poderes de la Unión, en diversos artículos.

La Ley Federal de Responsabilidades Administrativas de los Servidores Públicos (LFRASP), ${ }^{16}$ hace referencia al concepto recursos públicos federales en los numerales 2 y 8.

La Ley de Responsabilidad Patrimonial del Estado (LRPE), ${ }^{17}$ utiliza la expresión recursos, con referencia a recursos presupuestales en los numerales 6,11 y 35 .

La Ley Federal de Responsabilidad de los Servidores Públicos (LFRSP), ${ }^{18}$ refiere en los numerales 2 y 7 la expresión recursos económicos federales, en el numeral 5, recursos federales, y en el artículo 47, recursos. La expresión ingresos ilícitos se menciona una vez en el numeral 84.

La Ley Federal de Presupuesto y Responsabilidad Hacendaria (LFPRH) ${ }^{19}$ hace referencia a diferentes expresiones: recursos públicos federales, recursos del presupuesto, recursos presupuestales, recursos remanentes, ejercicio de recursos y recursos acumulados en diversos artículos. La expresión ingresos también es utilizada en diversos numerales.

La Ley de Fiscalización y Rendición de Cuentas de la Federación (LFRCF) ${ }^{20}$ emplea las expresiones: recursos, recursos públicos, recursos públicos federales, recursos presupuestales en diversos numerales. La expresión ingresos también es utilizada en diferentes artículos.

\footnotetext{
${ }^{16}$ DOF 13 de marzo del 2002, reformada en 12 ocasiones, la más reciente el 18 de diciembre de 2015.

${ }^{17}$ DOF 31 de diciembre de 2004, reformada en dos ocasiones, la más reciente el 12 de junio de 2009.

${ }^{18}$ DOF 31 de diciembre de 1982, reformada en 14 ocasiones, la más reciente el 18 de julio de 2016.

${ }^{19}$ DOF 30 de marzo de 2006, reformada en 11 ocasiones, la más reciente el 30 de diciembre de 2015.

${ }^{20}$ DOF 18 de julio de 2016, sin reforma.
} 
El Presupuesto de Egresos de la Federación para el Ejercicio Fiscal 2017 (PEF) ${ }^{21}$ también emplea los conceptos de ingresos y egresos.

La Ley de Ingresos de la Federación para el Ejercicio Fiscal 2017 (LI) ${ }^{22}$ utiliza de igual forma el concepto ingresos.

Pero ninguna de estas disposiciones normativas define qué se entiende por recursos públicos o ingresos o expresiones equivalentes o semejantes, por lo anterior debe entenderse por recursos públicos a aquellas riquezas que devengan a favor del Estado para cumplir sus fines y que en tal carácter ingresan en su tesorería.

\section{Opiniones diversas}

El Pleno en Materia Administrativa del Primer Circuito del Poder Judicial de la Federación dictó jurisprudencia, ${ }^{23}$ en la cual se sostiene que tiene el carácter de información pública la que se encuentra en posesión de Petróleos Mexicanos y sus organismos subsidiarios relativa a los recursos públicos entregados al Sindicato de Trabajadores Petroleros de la República Mexicana por concepto de prestaciones laborales contractuales a favor de sus trabajadores.

A lo anterior se suma la jurisprudencia ${ }^{24}$ de la Segunda Sala de la SCJN en la que se sostiene que no tiene carácter de información pública el monto anual de las cuotas sindicales de los trabajadores de Petróleos Mexicanos, mismas que forman parte del patrimonio del sindicato.

En sentido opuesto se ha manifestado el INAI, al haber resuelto en 2016, 47 recursos de revisión (PULSO LABORAL. http://elpulsolaboral.com.mx/sindicatos/8146/aprieta-inai-a-sindicatos Consultado: 13 de febrero de 2017) interpuestos por ciudadanos inconformes con las respuestas

\footnotetext{
${ }^{21}$ DOF 30 de noviembre de 2016, sin reforma.

22 DOF 15 de noviembre de 2016, sin reforma.

${ }^{23}$ Tesis: PC. I. A. J/2 A (10a.) Pelos de Circuito. Gaceta del Semanario Judicial de la Federación. Décima Época. Libro 21, agosto de 2015, Tomo II, p. 1484. Registro: 2009686.

${ }^{24}$ Tesis: 2a./J. 118/2010 (10a.) Segunda Sala. Semanario Judicial de la Federación y su Gaceta. Novena Época. Tomo XXXII, agosto de 2010, p.438. Registro: 164033.
} 
de sindicatos a solicitudes de información pública, entre los que son de señalarse el Sindicato de Trabajadores Petroleros de la República Mexicana (STPRM), Sindicato Nacional de Trabajadores de la Universidad Nacional Autónoma de México, Sindicato Nacional de Trabajadores de la Educación (SNTE) y Sindicato de Vanguardia Nacional de los Trabajadores de la Secretaría de Comunicaciones y Transportes.

De igual forma lo han hecho los comisionados del propio INAI al expresar que "los sindicatos tienen la obligación de declarar, de ser transparentes, de rendir cuentas en todos aquellos gastos que tengan de los recursos públicos que puedan recibir por cualquier razón, de ninguna manera estamos hablando de las cuotas de los trabajadores, eso es patrimonio del sindicato y sobre eso nada tenemos que hacer". El Sol de México. https://www.elsoldemexico.com.mx/mexico/210865-desde-hoy-sindicatos-obligados-a-rendircuentas Consultado: 17 de enero de 2017).

\section{Discusión}

Los sindicatos reciben, por lo general, de sus patrones, en cumplimiento de los contratos colectivos de trabajo, de los contratos ley y de las condiciones generales de trabajo, recursos que en dichos documentos se señalan como destinados a que el sindicato cumpla con sus agremiados con prestaciones como son festejos del Día de las Madres, del Día del Niño, de fechas navideñas, becas, descuentos para aparatos ortopédicos y equipo oftalmológico, préstamos personales y otros.

Los patrones que en este tema están obligados son los de organismos descentralizados y los de la administración pública federal y local, los cuales, en acatamiento al presupuesto de egresos que corresponda, reciben recursos destinados a cumplir con dichas obligaciones laborales y burocráticas.

Por lo anterior, al momento en que los sindicatos reciben los recursos señalados, éstos pasan a formar parte de su patrimonio, junto con las cuotas que cubren los agremiados, al igual que premios de sorteos, donaciones, legados y herencias de los cuales pudieran ser beneficiarios. 
En consecuencia, los obligados a transparencia y rendición de cuentas son los patrones antes señalados y no los sindicatos, los cuales tienen únicamente esta obligación con sus agremiados.

Para el caso de que esto fuera en otro sentido, también los particulares que en algún momento reciben reembolsos en relación a su declaración de impuestos, deberían apegarse a criterios de transparencia y rendición de cuentas, puesto que el reembolso se hace de recursos públicos.

\section{Conclusiones}

De lo anteriormente expuesto, se concluye que se deben derogar las disposiciones normativas que obligan a los sindicatos a transparencia y rendición de cuentas al INAI y a terceros.

Igualmente, se debe fomentar la obligación de los sindicatos de rendir cuentas a sus agremiados $\mathrm{y}$, para el caso de incumplimiento, aplicarse las sanciones que estatutariamente correspondan. 


\section{Bibliografía}

Aristegui noticias "Sindictos deben rendir cuentas por obligación contitucional: INAI", 2 de septiembre de 2015. http://aristeguinoticias.com/0209/mexico/sindicatos-deben-rendircuentas-por-obligacion-constitucional-inai/Consultado: 3 de junio de 2017.

Anzurez Gurría, J.J. (2014). "Sobre la democracia sindical. A propósito de la reforma laboral de 30 de noviembre de 2012", en Cuestiones Constitucionales. Revista Mexicana de Derecho Constitucional. Instituto de Investigaciones Jurídicas. Universidad Nacional Autónoma de México. Número 30, enero - junio de 2014, México.

Baena, G. (1998). Manual para elaborar trabajos de investigación documental. Editores Mexicanos Unidos, S.A., México.

El Sol de México. https://www.elsoldemexico.com.mx/mexico/210865-desde-hoy-sindicatosobligados-a-rendir-cuentas Consultado: 17 de enero de 2017.

Hernández Estévez, S. y López Durán, R. (1998). Técnicas de Investigación Jurídica. Oxford University Press, México.

Instituto Nacional de Transparencia, Acceso a la Información y Protección de Datos Personales. Acuerdo Act-ext-PUB/02/05/2016.2 Sindicatos. Nos. 60100 a 60256. DOF. http://dof.gob.mx/nota_detalle.php?codigo=5436061\&fecha=04/05/2016 Consultado: 15 de febrero de 2017.

Junta Federal de Conciliación y Arbitraje. http://www.gob.mx/jfca Consultado: 1 de febrero de 2107.

Lastra Lastra, José Manuel. "El sindicalismo en México", en Anuario Mexicano de Historia del Derecho. Volumen XIV, UNAM. https://revistascolaboracion.juridicas.unam.mx/index.php/anuario-mexicano-historiader/article/view/29632/26755 Consultado: 27 de enero de 2017.

Pulso laboral. http://elpulsolaboral.com.mx/sindicatos/8146/aprieta-inai-a-sindicatos Consultado: 13 de febrero de 2017.

Rojas Soriano, R. (1979). Guía para realizar investigaciones sociales. Universidad Nacional Autónoma de México, México.

Trueba Urbina, A. (1981). Nuevo derecho del trabajo, Editorial Porrúa, S.A., México. 
Secretaría del Trabajo y de la Previsión Social http://www.gob.mx/stps/ Consultado: 13 de febrero de 2017.

Tribunal Federal de Conciliación y Arbitraje. http://tfca.gob.mx/es/TFCA/ Consultado: 13 de febrero de 2017.

Ugalde, L. C. (2015). Rendición de cuentas y democracia. El caso de México. Cuadernos de divulgación de la cultura democrática, no. 21. Instituto Nacional Electoral, México.

\section{De consulta periódica}

Diario Oficial de la Federación, diversas fechas.

Jurisprudencia. Semanario Judicial de la Federación y su Gaceta. Diversas fechas.

Boletín oficial del Gobierno del Estado de Baja California Sur, 23 de febrero de 2004.

Sección segunda del periódico oficial del Estado de San Luis Potosí, 8 de enero de 1996.

Periódico Oficial del Estado de Puebla, 11 de diciembre de 2013.

Periódico Oficial, Gaceta del Estado de México, 7 de junio de 2002.

Periódico Oficial del Estado de Morelos, 13 de octubre de 1993. 